\title{
Quiebras de la cronología y sentido: una aproximación narratológica a De la vida de las marionetas
}

\section{Breakdowns of the chronology and sense: a narratological approach to From the Life of the Marionettes}

\author{
Rodríguez Serrano, A. y Planes Pedreño, J. A. ${ }^{1}$ \\ Recibido: 9-04-2019 - Aceptado: 12-08-2019 \\ DOI: https://doi.org/10.26441/RC18.2-2019-A15
}

\begin{abstract}
RESUMEN: El presente artículo propone una aproximación a una de las películas menos estudiadas del director sueco Ingmar Bergman: De la vida de las marionetas (Aus dem Leben der Marionetten, 1980). Nos interesa sobre todo el estudio de la forma fílmica y las huellas enunciativas como generadoras de significados. Por ello, recurriremos a una metodología híbrida en la que se combina el análisis de corte estructural del relato con la aplicación de procesos de microanálisis narratológico. Pretendemos demostrar cómo las decisiones estrictamente formales responden de manera íntima a la pregunta sobre el sentido que desencadena el drama y la complejidad de los personajes. Este propósito nos conduce a dividir los campos de análisis en tres categorías concretas: la cronología de la diégesis (fricciones entre el tiempo del relato y de la historia), el sistema de narradores y la gestión temporal del punto de vista (las implicaciones significantes del flashback y el flashforward en particular).
\end{abstract}

Palabras clave: narrativa audiovisual; análisis estructural; Ingmar Bergman; de la vida de las marionetas; flashback; análisis fílmico.

\begin{abstract}
The present article proposes an approach to one of the less studied films of the Swedish director Ingmar Bergman: From the life of the Marionettes (Aus dem Leben der Marionetten, 1980). We are particularly interested in the study of the filmic form and the traces of the enunciation as generators of meanings. Therefore, we will use a hybrid methodology that combines the structural analysis of the story with the application of formal microanalysis processes. We intend to demonstrate how strictly formal decisions respond intimately to the question of the meaning that triggers the drama and the complexity of the characters. We will divide the fields of analysis into three specific categories: the chronology of the diegesis (frictions between the time of the story and the time of the film), the system of narrators and the temporal management of the point of view (especially in the significant implications of flashbacks and flash-forwards).
\end{abstract}

Keywords: audiovisual narrative; structural analysis; Ingmar Bergman; from the life of the marionettes; flashback; film analysis.

\footnotetext{
${ }^{1}$ Aarón Rodríguez Serrano es Doctor en Comunicación Audiovisual por la Universitat Jaume I y Profesor Ayudante Doctor de la Narrativa audiovisual en la Facultad de Ciencias Humanas y Sociales de la misma universidad. serranoa@uji.es, http://orcid.org/0000-0002-3858-1045

José Antonio Planes Pedreño es Doctor en Comunicación Audiovisual por la Universidad Católica de Murcia y Profesor de Taller de Narrativa Audiovisual en la Facultad de Comunicación de la Universidad de Medellín.jplanes@udem.edu.co, https://orcid.org/0000-0002-9133-9610
} 


\section{Introducción}

El presente artículo pretende realizar una exploración narratológica sobre De la vida de las marionetas (Aus dem Leben der Marionetten, Ingmar Bergman, 1980), una de las obras menos estudiadas de la amplia trayectoria del director sueco. Obra que, además, funciona como una suerte de texto excéntrico en el seno de su filmografía y que, por ello, merece la pena ser estudiado monográficamente.

En primer lugar, merece la pena contextualizar brevemente la obra para entender algunas de las modificaciones sobre los estilemas anteriores de la filmografía del director. De la vida constituyó la última pieza audiovisual dirigida por Bergman en Alemania, tras su autoexilio forzado por un escándalo con el fisco. Fue concebida y realizada como un producto para televisión, hasta el punto de que el propio autor lamentaría con posterioridad su explotación cinematográfica (Bergman, 2001: 185). En segundo lugar, con la excepción de la fotografía de Sven Nykvist, el resto de los miembros del equipo son prácticamente desconocidos en el particular universo bergmaniano. Además de esto, sus localizaciones - principalmente urbanas y cosmopolitas, levantadas en un espectro visual totalmente opuesto al de las "películas de Färo" (Steene, 2005: 40)- propician una gestión del espacio y de la iluminación completamente diferente, de ahí la apuesta por un manifiesto feísmo -véase, por ejemplo, la dirección de arte del prostíbulo-, que prescinde de muchos de los elementos que habían ido configurando la huella escritural del director en las dos décadas anteriores. Esto le invitará a tomar decisiones formales de planificación y encuadre inusuales en su construcción de la forma fílmica, como los brutales picados ensayados en el despacho del protagonista o los planos contextuales del tejido urbano alemán. Este tipo de decisiones generan una brecha frente a la manera anterior en la que la propia dimensión del cuerpo humano había sido situada en el encuadre -recordemos, por ejemplo, el modo de situar la verticalidad de las figuras en contraposición con la horizontalidad del mar de Färo o con las texturas "rurales" ofrecidas por la madera, la roca, el cristal de las cabañas. El exilio de Bergman no nos parece una simple anécdota contextual, sino que domina por completo todas las direcciones artísticas sobre el profílmico. Se trata, por tanto, de una cinta que, siendo plenamente deudora de los estilemas (Font, 2002) propios del director, ejerce también una notable tensión dentro de los procesos habituales de significación formal (Zunzunegui, 2016) que caracterizan los planteamientos expresivos del director sueco.

En términos narratológicos, la película se apoya sobre una estrategia de distanciamiento que únicamente en una aproximación introductoria podría considerarse como brechtiana. En esta dirección, nuestro estudio se sumará a las intuiciones de teóricos como Susan Sontag (1967: 140), Robin Wood (1994: 63) o Christopher Orr (2000: 102), quienes consideraron que la apropiación por parte de Bergman de recursos propios de la teoría dramática de Brecht (2004) responde, en realidad, a un proceso inverso en el que la identificación con el espectador sigue manteniendo intactos los flujos de identificación con el universo fílmico, si bien desde una postura inevitablemente más madura. De la vida podría constituir una perfecta ejemplificación de ese hipotético "espectador emancipado" de Jacques Rancière (2010) en tanto en cuanto se edifica a partir de los inevitables procesos de afección emocional propios de la experiencia fílmica en su dimensión formal (Zumalde, 2011), pero también de los temblores propios de las grandes preguntas sobre el sentido que laten bajo la tramoya cinematográfica. En efecto, Bergman genera un espacio para la participación activa del espectador-después de todo, se le invita no únicamente a reordenar la cronología del relato-, pero al mismo tiempo maneja elementos narrativos propios de géneros emocionalmente opuestos como el melodrama. 
Podemos justificar dicha afirmación valiéndonos de la clasificación de motivos melodramáticos que señala Francisco Javier Gómez Tarín en un texto reciente:

El melodrama (...) se fundamenta en la presencia de un personaje melancólico mientras el espectador cobra plena conciencia de la herida del tiempo, metaforizada mediante un objeto simbólico: lo gestual se antepone a lo verbal y la catálisis adquiere un mayor relieve en el curso de la narración, en la que el espectador obtiene un saber (focalización) superior al que los personajes poseen (Gómez Tarín, 2018: 41).

El trabajo citado resulta pertinente en la medida en que pone de manifiesto que estos patrones se aplican, precisamente, en aquellas cintas que no pueden ser consideradas formalmente melodramas clásicos. Si anticipamos rasgos del análisis que desplegaremos en los siguientes epígrafes, descubriremos que se cumplen todos los puntos: por ejemplo, contaremos con un personaje herido en el terreno afectivo -arrasado por una patología que, siempre con cierta precaución, arrastrará una sintomatología cercana a la melancolía en su acepción explícitamente cultural (Berenstein, 2011)- cuya metáfora precisa es el célebre objeto de peluche que reproduciremos en la figura 10. Más provechoso para nuestra aproximación será el problema de la relación entre herida del tiempo y saber (focalización), ya que, como demostraremos, ese es el punto de encuentro exacto entre los sistemas de distanciamiento brechtianos y la quemadura afectiva propia del melodrama: el hecho de ofrecer la información al espectador mediante carteles explicativos y de arrancar la película en el gesto catastrófico que lo arrasa todo -el asesinato de una prostituta - genera la compleja experiencia textual de la cinta, y dicho sea de paso, lo que realmente separa De la vida tanto de los thrillers como de las películas sobre la "incomunicación matrimonial" que se realizaban en su momento.

En este aspecto, y siguiendo aproximaciones como la de Marsha Kinder (1981), parece plausible que De la vida pueda ser encajada entro de la particular indagación de Bergman a propósito del determinismo y de la manera en la que ciertos actos trágicos se experimentan como inevitables. La figura del dios-marionetista está presente de manera palmaria en sus primeros trabajos teatrales de la década de los treinta (Gado, 1986: 98), especialmente en Kaspers död (Sjögren, 2002) y en Jack hos skandespelarna (Bergman, 1946). La exploración continuará abierta prácticamente hasta su último largometraje en celuloide -Fanny y Alexander (Fanny öch Alexander, 1982)-, y sus últimos montajes escénicos para televisión. Lo que aleja a De la vida del resto de producciones citadas -y aquí se encuentra, de alguna manera, nuestra hipótesis de partida-es que la mostración de esa problemática determinista se plantea desde una posición narratológica extrañamente inusual: la ruptura estructural de la linealidad narrativa en las relaciones causa-efecto. O lo que es lo mismo: las quiebras de su cronología. Esto, junto a las razones ya mencionadas, garantiza la pertinencia de nuestro objeto de estudio: como tendremos ocasión de demostrar, De la vida es la obra más compleja en términos de gestión temporal y focalización de la trayectoria bergmaniana, y creemos que un análisis estructural detallado de la misma podría tener interés dentro del campo general de los estudios fílmicos para comprender con mayor profundidad la voluntad experimental y las aportaciones de Bergman al campo del flashback y de la declinación del punto de vista.

Merece la pena, en esta dirección, realizar un breve excurso que indague en la implicación filosófica de esa quiebra espacio-temporal a la que hacíamos referencia anteriormente. En cierto sentido, la obra de Bergman está íntimamente relacionada con una serie de pensadores existencialistas (Puigdomènech, 2004) de los que recoge -a riesgo de sintetizar demasiado- la quiebra de la fundamentación del sentido de la vida en marcos simbólicos donde la cohesión temporal estaba garantizada. La introducción de perspectivas intempestivas o ahistoricistas (Astor, 2018) contra los lugares comunes del 
pensamiento occidental desembocaron en un cuestionamiento de la linealidad de la propia vida humana cuyo matiz más refinado sea, quizá, el desarrollo de los éxtasis de la temporeidad en la obra del primer Martin Heidegger (2009). Por mucho que -como ha señalado Alejandro Escudero (2017) - ese proyecto inicial incurriera en una serie de aporías en las que se repite inevitablemente el gran problema sujeto/objeto de la metafísica tradicional, lo que aquí nos interesa más bien es que en su salto hacia la filosofía del arte -y mucho más concretamente, hacia la filosofía del relato-, el concepto de ser humano no encuentra una garantía apriorística de su sentido en la aparente recepción cronológico-lineal de su tiempo. Dicho con mayor claridad, y ya en relación con la película de Bergman: la explicación de su propia existencia - ese haz de relatos, olvidos, deslizamientos y recuerdos con el que pretendemos explicar lo que nos ocurreno se puede fijar sobre un tiempo lineal asentado, a su vez, sobre un "gran relato" (Lyotard, 1986) del que se desprenda metafísicamente un sentido. Desde aquí podemos justificar dos de las decisiones discursivas que tomaremos en el artículo:

1) Al considerar el "punto cero" del relato el asesinato de la prostituta -véase el epígrafe 2.2. - estamos poniendo en valor el problema ético del asesinato en nuestra lectura, y más concretamente, la extraordinaria dificultad de experimentarlo como tal en un mundo en el que cada ciudadano debe hacerse cargo de su propio sentido. Esto, indudablemente, entra en relación con la propia quiebra existencial del protagonista: allí donde no hay un marco simbólico - ya sea religioso, ya sea político- en el que se pueda desplegar la importancia de la vida humana, ¿qué es lo que otorga valor a la vida humana del otro?

2) El tomar la estructura de la cinta como el objeto privilegiado del artículo se justifica plenamente toda vez que es la propia quiebra de la seguridad existenciario-temporal la que está en crisis en la segunda mitad del siglo XX -momento en el que se genera la cinta-, pero también, todo sea dicho, en nuestros días. En efecto, frente al triunfo de un cientifismo que amenaza con convertirse en el sistema de saber dominante (Català Domenech, 2016), es necesario contraponer nuevas maneras de pensar las quiebras de la escritura cinematográfica como un modo privilegiado de dar voz a ese sujeto confuso que emerge de la angustia postmoderna (Palao-Errando, Loriguillo-López y Sorolla-Romero, 2018).

A fin de poder ahondar en esta cuestión, haremos uso de una metodología de análisis narratológico-estructural que haga especial hincapié en la disposición cronológica con la que el espectador accede a los acontecimientos. Para ello, seguiremos la siguiente estrategia: en primer lugar, desglosaremos el funcionamiento de la cinta en lexías (unidades significantes) y gestión del tiempo narratológico. Esto nos permitirá ubicar un hipotético tiempo cero del relato -el asesinato de la prostituta K. a manos del protagonista- sobre el que dilucidaremos los procesos de construcción de sentido narratológico-temporal de la enunciación. A partir de dicho movimiento desplegaremos el sistema de narradores de la cinta, la articulación estructural y el sistema de flashbacks/flashforwards que organiza la información. Por último, sistematizaremos los datos más relevantes de la investigación en las preceptivas conclusiones.

\section{Análisis estructural}

\subsection{Despliegue estructural de la cinta}

Como ya se ha comentado anteriormente, el film está dispuesto por unidades de relato independientes, generalmente introducidas por un crédito escrito en un sobrio negro sobre blanco que parece remitir a la tipografía propia de una máquina de escribir. Más adelante, 
al analizar el sistema de narradores (epígrafe 2.2.), tendremos ocasión de volver sobre esta idea. Por el momento, y con vistas a generar una tabla de códigos que nos permita trabajar con cierta precisión durante el resto del artículo, proponemos la siguiente clasificación en lexías de análisis. La decisión de trabajar con este tipo de unidad por encima de otras categorías clásicas como escena, secuencia o incluso fragmento viene dada, además de por la propia tradición del análisis estructural (Barthes, 1970; Aumont y Marie, 1990), o por la existencia de análisis de la obra de Bergman ya publicados en esta dirección (Rodríguez Serrano, 2017; González Hortigüela, 2017), por la comodidad con la que nos permite atender a los procesos de significación concretos. Como ya teorizó Roland Barthes al respecto:

La lexía comprenderá unas pocas veces unas pocas palabras, y otras algunas frases, será cuestión de comodidad: bastará con que sea el mejor espacio posible donde se puedan observar los sentidos; su dimensión, determinada empíricamente a ojo, dependerá de la densidad de las connotaciones, que es variable según los momentos del texto: simplemente se pretende que en cada lexía no haya más de tres o cuatro sentidos que enumerar, como máximo (Barthes, 1980: 9).

Hay, asimismo, otras razones que justifican la elección de esta unidad. En primer lugar, parece sensato que, si nuestra voluntad pasa por utilizar una metodología estructuralista, tomemos como referencia $S / Z$ como el trabajo canónico en el campo -sabiendo, obviamente, que los tránsitos entre semiología literaria y fílmica deben contar con los rudimentos concretos de cada campo estético. En segundo lugar, la propia estructura de la cinta está dividida en una serie de segmentos que no admiten con facilidad las unidades clásicas: tomemos como ejemplo el fragmento 2 según la tabla que reproducimos a continuación. En su interior lo dividimos en tres lexías que no coinciden sistemáticamente con la clasificación secuencia o escena, y cuyo interés de cara al análisis es, precisamente, su relevancia temática. Así, es el contenido narratológico el que predomina por encima de una simple partición mecánica en unidades de tiempo/espacio. Parece obvio, además, que la propia película aliente este tipo de aproximaciones en razón de que ella misma no responde a los parámetros tradicionales del cine clásico -recuérdese, por ejemplo, que hasta el propio Christian Metz (2002: 236) tuvo que modificar su sistema más o menos rígido de clasificación sintagmática al toparse con el análisis del cine de Godard.

Para explorar la ruptura temporal tomaremos como referencia la distinción cronológica clásica de Gaudreault y Jost (1995: 113, la cual nos permite situar como punto 0 el suceso central (el asesinato de una prostituta a manos de Peter Egerman) con el propósito de localizar el uso de flashbacks y flashforwards, tendremos ocasión de desarrollarlo con mayor amplitud en el epígrafe 2.4.

Tabla 1. Desglose estructural del film.

\begin{tabular}{|c|c|c|c|}
\hline $\begin{array}{l}\text { Fragmento } \\
\text { según el orden } \\
\text { del montaje }\end{array}$ & Breve descripción & Tiempo del relato & División en lexías \\
\hline 01 & $\begin{array}{l}\text { Asesinato de K. (la } \\
\text { prostituta) }\end{array}$ & 0 & L1: Asesinato \\
\hline \multirow[t]{3}{*}{02} & \multirow{3}{*}{$\begin{array}{l}\text { Encuentro entre el } \\
\text { psiquiatra (Morgan Jensen) } \\
\text { y el inspector. }\end{array}$} & \multirow{3}{*}{$\begin{array}{l}20 \text { horas después } \\
\text { del asesinato. }\end{array}$} & L2: Morgan y el inspector \\
\hline & & & $\begin{array}{l}\text { L3: Flashback sobre el Tiempo } \\
0 \text { del relato }\end{array}$ \\
\hline & & & L4: Morgan y el inspector \\
\hline
\end{tabular}




\begin{tabular}{|c|c|c|c|}
\hline \multirow[t]{4}{*}{03} & \multirow{4}{*}{$\begin{array}{l}\text { Sesión de análisis entre } \\
\text { Morgan y Peter. Intento de } \\
\text { encuentro sexual entre } \\
\text { Morgan y Katarina. }\end{array}$} & \multirow{4}{*}{$\begin{array}{l}14 \text { días antes del } \\
\text { asesinato. }\end{array}$} & L5: Sesión analítica \\
\hline & & & L6: Fantasía del asesinato \\
\hline & & & L7: Infidelidad. \\
\hline & & & $\begin{array}{l}\text { L8: Conversación tras el coito } \\
\text { frustrado. }\end{array}$ \\
\hline \multirow[t]{2}{*}{04} & \multirow{2}{*}{$\begin{array}{l}\text { Encuentro entre el inspector } \\
\text { y la madre de Peter. }\end{array}$} & \multirow{2}{*}{$\begin{array}{l}\text { Una semana } \\
\text { después del } \\
\text { asesinato. }\end{array}$} & L9: Interrogatorio \\
\hline & & & $\begin{array}{l}\text { L10: Flashback sobre la última } \\
\text { visita de Peter a su madre. }\end{array}$ \\
\hline \multirow[t]{2}{*}{05} & \multirow{2}{*}{$\begin{array}{l}\text { Conversación nocturna } \\
\text { entre Peter y Katarina. } \\
\text { Trabajo de Peter. }\end{array}$} & \multirow{2}{*}{$\begin{array}{l}5 \text { días antes del } \\
\text { asesinato. }\end{array}$} & L11: Conversación marital \\
\hline & & & $\begin{array}{l}\text { L12: Peter dictando a su } \\
\text { secretaria }\end{array}$ \\
\hline \multirow[t]{2}{*}{06} & \multirow[t]{2}{*}{ Vida profesional de Katarina } & \multirow[t]{2}{*}{$\begin{array}{l}4 \text { días antes del } \\
\text { asesinato. }\end{array}$} & $\begin{array}{l}\text { L13: Encuentro en el taller de } \\
\text { costura }\end{array}$ \\
\hline & & & $\begin{array}{l}\text { L14: Charla entre Katarina y } \\
\text { Tim en el bar }\end{array}$ \\
\hline 07 & Interrogatorio de Tim & $\begin{array}{l}3 \text { días después del } \\
\text { asesinato. }\end{array}$ & L15: Interrogatorio. \\
\hline \multirow[t]{2}{*}{08} & \multirow[t]{2}{*}{ Carta fantaseada de Peter } & \multirow{2}{*}{$\begin{array}{l}\text { Secuencia fuera } \\
\text { del tiempo } \\
\text { cronológico del } \\
\text { film }\end{array}$} & L16: Fantasía interna de Peter \\
\hline & & & $\begin{array}{l}\text { L17: Despertar en mitad de la } \\
\text { noche. }\end{array}$ \\
\hline \multirow[t]{2}{*}{09} & \multirow[t]{2}{*}{ Intento de suicidio de Peter } & \multirow{2}{*}{$\begin{array}{l}1 \text { día antes del } \\
\text { asesinato. }\end{array}$} & L18: Intento de suicidio \\
\hline & & & L19: Conversación marital \\
\hline 10 & $\begin{array}{l}\text { Encuentro entre Katarina y } \\
\text { la madre de Peter }\end{array}$ & $\begin{array}{l}3 \text { semanas } \\
\text { después del } \\
\text { asesinato. }\end{array}$ & L20: Conversación \\
\hline \multirow[t]{4}{*}{11} & \multirow[t]{4}{*}{$\begin{array}{l}\text { Tiempo previo al asesinato } \\
\text { de K. }\end{array}$} & \multirow[t]{4}{*}{$\begin{array}{l}50 \text { minutos antes } \\
\text { del asesinato. }\end{array}$} & $\begin{array}{l}\text { L21: Entrada de Peter en el } \\
\text { prostíbulo }\end{array}$ \\
\hline & & & L22: Redada de la policía \\
\hline & & & $\begin{array}{l}\text { L23: Conversación en el } \\
\text { camerino }\end{array}$ \\
\hline & & & $\begin{array}{l}\text { L24: Conversación en el } \\
\text { escenario }\end{array}$ \\
\hline \multirow[t]{2}{*}{$\begin{array}{l}12 \text { y } 13 \\
\text { (epílogo) }\end{array}$} & \multirow[t]{2}{*}{$\begin{array}{l}\text { Centro de reclusión } \\
\text { psiquiátrica }\end{array}$} & \multirow{2}{*}{$\begin{array}{l}4 \text { semanas } \\
\text { después del } \\
\text { asesinato. }\end{array}$} & $\begin{array}{l}\text { L25: Informe psiquiátrico de } \\
\text { Peter }\end{array}$ \\
\hline & & & $\begin{array}{l}\text { L26: Conversación final entre } \\
\text { Katarina y Morgan. }\end{array}$ \\
\hline
\end{tabular}

Fuente: Elaboración Propia.

Pese a la aparente claridad de la disposición estructural, Bergman se cuida mucho de facilitar la lectura del espectador. Por poner apenas un par de ejemplos, un fundido a negro - que coincide, por cierto, con la relación sexual frustrada entre Morgan y Katarinadivide explícitamente las lexías 7 y 8 , mientras que podemos observar encabalgamientos en el montaje entre diferentes lexías (por ejemplo, la 10 o la 13). Con esto queremos señalar que, incluso en el interior de las secuencias, Bergman introduce elipsis y fracturas 
temporales que dislocan todavía más, si cabe, la experiencia del espectador. Un comentario aparte merecerá las lexías en las que se desarrollan explícitamente flashbacks expositivos e independientes, a los que volveremos con posterioridad.

\subsection{El tiempo 0 del relato: un cadáver.}

Pasando ya a la disposición temporal del film, lo primero que nos llama la atención es la manera en la que la película asume que el asesinato es necesariamente el punto 0 del relato. El centro de la significación sobre el que se levanta la colección de delirios, conversaciones, confesiones y traiciones es, por fuerza, un cuerpo muerto. Cuerpo que, además, resulta poco menos que anecdótico en el desglose narrativo del largometraje: nada sabremos de K., más allá de esa enigmática inicial de su nombre que la hermana en espejo con la mujer de su asesino y de sus últimos cincuenta minutos de vida. Mientras que Bergman despliega su cámara en los espacios públicos y privados de sus protagonistas, la quiebra de su relato - marcada por la enunciación con la muy pertinente palabra alemana Katrastrophe, que resuena inevitablemente con la inicial de la víctima y con la propia Katarina- viene dada por un cuerpo que se puede asumir como intercambiable, casi azaroso.

La propia disposición visual de la cinta reflexionará autoirónicamente sobre esta idea en varios momentos. Por ejemplo, el encabalgamiento entre las lexías 20 y 21 a las que hacíamos referencia anteriormente se despliega a partir de un juego perverso de montaje: de un primer plano silencioso de Katarina (Fig. 1), Bergman pasa por corte directo a un plano detalle de una mujer desnuda contorsionándose al ritmo de la música en el prostíbulo (Fig. 2). La escala cerrada de plano y la propia duración del encuadre-cuarenta segundos-generan una inevitable incomodidad en el hecho mismo de mirar ese cuerpo seccionado, sin rostro, reducido en lo esencial a una carne temblorosa que se ofrece de manera mecánica. Esta ausencia de identidad en la bailarina parece sugerir a priori que se podría tratar de la propia $\mathrm{K}$. ofreciendo su espectáculo antes de ser asesinada. Sin embargo, un movimiento de cámara ascendente acompañado de un cambio de foco reencuadra mediante yuxtaposición interna el rostro pensativo y apesadumbrado de la futura víctima (Fig. 3).

Figuras 1, 2 y 3. De la vida de las marionetas.
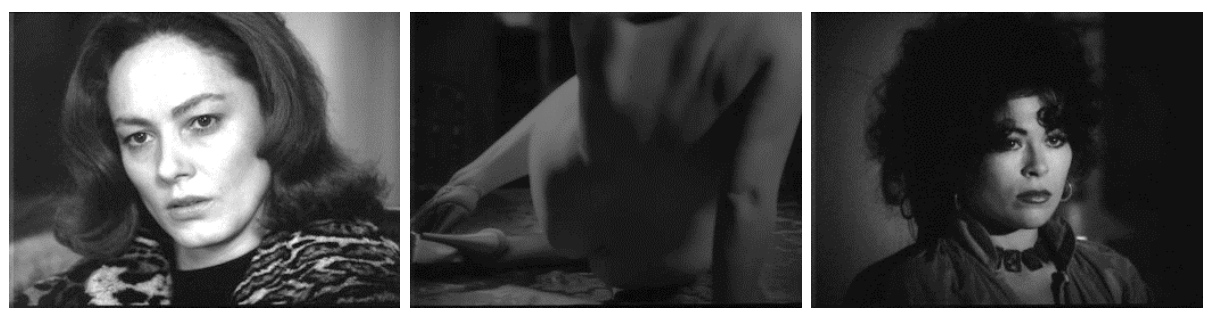

Fuente: Edición DVD de Filmax.

Es evidente que Bergman está generando una cadena significante entre ambas mujeres que viene dada, precisamente, por la naturaleza de ese acto sexual que se introduce explícitamente entre ambas. Sin embargo, son dos rostros que funcionan desde dimensiones narrativas necesariamente opuestas: Katarina es el ser sexuado por defecto -situada en una sensación de infelicidad permanente que ninguno de sus amantes puede aplacar y que para nada es compatible con los verdaderos deseos de su esposo (Humphrey, 2013: 170)-, mientras que K. es el ser sexuado por exceso -sometida a la rueda implacable de clientes que la utilizan para situar su cuerpo en posiciones afectivas que nada tienen que ver con ella. El primer plano de ambas mujeres parece detenerse en 
momentos diferentes de una precisa intimidad, si bien la iluminación y el rictus de K. no dejan lugar alguno a la duda: la suya es una posición en el relato mucho más desesperada y oscura. Se trata, sin duda, de una sutil incorporación por parte del director al personaje de K. dentro de ese mundo de hombres y mujeres/marioneta dominados por la angustia existencial que puntea el metraje.

Desde aquí, se puede entender la decisión bergmaniana de abrir la película precisamente con la mostración del asesinato de K. (Lexía 01). El hecho de que se arranque exponiendo el homicidio distancia automáticamente la ficción de los lugares comunes del thriller o de las películas detectivescas que parecen girar en torno a la investigación de un asesinato -su "horizonte de expectativas" (Krutnik, 2006)-, de tal modo que todo lo que después es posicionado frente al espectador debe leerse obligatoriamente ante la certeza y la inevitabilidad de la catástrofe. El punto 0 es definitorio por cuanto configura el tono mismo de la obra: no habrá esperanza posible, ni solución sorprendente para el caso investigado. No se introducirán pruebas a modo de punto de giro ni ninguno de los testimonios ofrecidos cambiará en lo más mínimo la brutalidad del acontecimiento. De hecho, por mucho que la película parezca sugerir en algunos momentos posibles "explicaciones" de la conducta violenta de Peter, lo único que queda es una cacofonía de sugerencias que procede, a su vez, por la pluralidad del sistema de narradores que conforman la cinta. Tendremos que explorar, por tanto, sus rasgos.

\subsection{Sistema de narradores}

La sistematización de los diferentes narradores que participan en una película es un tema realmente complejo que cuenta con una extensa bibliografía al respecto. Desde las aportaciones iniciales que aprovecharon la herencia semiótica para plantearse su traslación a la pantalla (Casetti, 1989), a las aproximaciones más recientes que actualizan dicha herencia a la luz de las evoluciones del cine contemporáneo (Machado, 2009), las instancias narrativas han formado una parte fundamental de la problemática narratológica. Bajo nuestro punto de vista, quizá la sistematización más compleja -que nosotros tomaremos como punto de partida- es que la desarrolló Francisco Javier Gómez Tarín en su ya canónico Elementos de narrativa audiovisual (2011: 79-84), si bien el lector interesado puede encontrar también una versión abreviada y actualizada en la correspondiente voz del Diccionario de conceptos y términos audiovisuales (GómezTarín y Marzal, 2015).

Ciertamente, De la vida es una cinta extraordinariamente compleja en lo que al sistema de narradores se refiere. Es necesario señalar que remite de muchas maneras a experimentos anteriores de Bergman, sintetizándolos y concretándolos. Por ejemplo, habíamos observado las escisiones entre actor y personaje en las falsas entrevistas de Pasión (En passion, 1969), o los juegos con las marcas enunciativas y la falsa transparencia que se retrotraen a los tiempos de Crisis (Kris, 1945). Aquí recuperará algunos de sus estilemas enunciativos tradicionales -la inserción de un meganarrador manifiesto, como el que se encontraba situado en la banda de sonido inicial de La hora del lobo (Vargtimmen, 1968), o de narradores diegéticos radicales que se refieren a sus fantasías, sus delirios o sus ensoñaciones.

En un primer nivel, contamos con la figura de un meganarrador (García Catalán y Sorolla Romero, 2014) que se manifiesta mediante al menos dos procesos significantes concretos. Los más obvios son los rótulos que sirven como separación entre los fragmentos narrativos principales, en los que siempre se establece una orientación temporal de los acontecimientos. Por mucho que su redacción se revista de cierta objetividad, la selección 
de ciertos matices léxicos -por ejemplo, la ya citada referencia a la catástrofe como un hipotético sinónimo del asesinato- permiten descifrar un temblor en la aparente omnisciencia de su pulso enunciativo. Un segundo proceso tendría que ver con el virado entre color y blanco y negro que abre y cierra la película -idea que retomaremos más adelante, en el análisis de la estructura cronológica del film.

Podríamos afirmar que el meganarrador dispone también de una instancia delegada para el propio espectador en el interior de la ficción, situada en la presencia del propio investigador que se encarga del caso. Como ocurre en tantas otras ficciones vinculadas con el género detectivesco (Marzal Felici, 2004), se genera así un sutil proceso de identificación que dominará la gestión de la información en términos que giran entre la expectación y el suspense (Díez Puertas, 2006: 276). Bergman genera sobre esta instancia una fricción narrativa realmente valiosa: por una parte, los créditos que separan las escenas imitan la tipografía de una máquina de escribir y parecen responder a la lógica gélida de los informes policiales (Fig. 4). Por otra parte, durante gran parte del metraje deja en fuera de campo al personaje del investigador, por lo que la puesta en cuadro se centra únicamente en los testimonios: los gestos, las vacilaciones, las pausas y las réplicas irónicas de aquellos que ofrecen su información al espectador. Sin embargo, una vez traspasada la mitad del metraje, Bergman se vale por primera vez de un plano/contraplano (Figs. 5 y 6) para mostrar a ese hipotético detective al espectador -un personaje que, como comentaremos más adelante, está lejos de ser diegéticamente relevante.

Figuras 4, 5 y 3. De la vida de las marionetas.
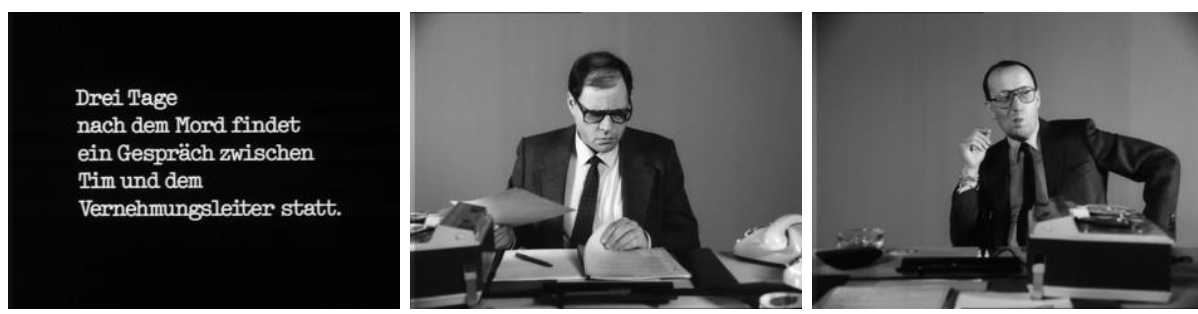

Fuente: Edición DVD de Filmax.

Debemos hacer notar que el detective, al igual que el propio espectador, sea presentado en una actitud de lectura y desciframiento de los acontecimientos (Figura 05). Se establece así una complicidad aparente entre los mecanismos del saber, propia del género policiaco, pero como ya hemos mencionado, plenamente dirigida por la mostración inicial del asesinato de K. Y, por cierto, no es en absoluto casual que esta extraña basculación de la posición del narrador/detective tenga lugar justo en el encuentro con Tim, escena capital toda vez que Bergman escribe, en ella, la sugerencia mayor sobre el trauma de Peter:

La única verdad del personaje que es -nuevamente- la de su máscara: esa superficie exterior elaborada para ser mentida en el espejo ante el cual se compone y que sólo esconde la dualidad deseante del sujeto, siempre oscilante entre la complacencia en sus propias deyecciones masoquistas - brutalidad, miedo, náusea- y un anhelo real de intimidad y de ternura (Company, 1999: 137).

Por debajo de esta instancia narrativa, la película desplegará toda una colección de puntos de vista que parece abarcar de manera apabullante cualquier posición narrativa con respecto al saber. Siguiendo un hipotético orden de transmisión narrativa, tenemos en primer lugar aquellos personajes que se dirigen directamente hacia el detective/espectador: el doctor Jensen (Lexía 02), la madre de Peter (Lexía 09) y Tim (Lexía 15) comparecen como narradores subjetivos y diegéticos de primer nivel, puesto 
que toman parte activa en los acontecimientos que muestran. En segundo lugar, accedemos a encuentros que no parecen ser narrados por ningún personaje y a los que no tendría acceso ningún hipotético detective: por ejemplo, las conversaciones nocturnas entre Peter y Katarina (Lexía 19). Una tercera y última categoría, la más interesante, es aquella en la que la narración parece remitir a una instancia omnisciente que, pese a lo que suele ser habitual, utiliza su saber para complejizar la narración en lugar de para simplificarla: sueños, cartas, fantasías...

Detengámonos en esta categoría. Si pensamos en la construcción de las lexías 6 y 16 -las referentes a las fantasías de Peter-, veremos cómo su funcionamiento filmográfico es extraordinariamente complejo. En ambos casos se trata de hipotéticas narraciones de Peter que tienen un destinatario intradiegético: ya sea a su analista o a su propia esposa, en una sesión terapéutica o en una carta nunca enviada. La película refuerza el problema mismo de la comunicación del desgarro -tema central del universo bergmaniano de los setenta (Wood, 2009)-, con la salvedad de que la enunciación es capaz de mostrar, de poner imágenes que acompañan, refuerzan o completan el propio uso de la voz en off del personaje. Se diría que el meganarrador es capaz de entregar a su espectador un cierto saber estrictamente visual del interior del personaje y generar con él una cadena significante especialmente densa.

Si casi todas las escenas de la obra están rodadas con una pesada iluminación en clave baja, con predilección por los interiores cargados y los espacios oscuros, las escenas del "interior de Peter" contrastan por la limpieza enunciativa y la composición tonal mucho más cercana al blanco cegador. Las imágenes des-velan el territorio del deseo homicida de Peter contra su propia mujer, pero también el complejo rol del cuerpo en su particular delirio y la imposibilidad de esa cercanía, esa afectividad de los cuerpos que se experimenta de manera tan dolorosa. En esencia, el personaje de Peter es pura pulsión de muerte que recorre las escenas atravesado por la inminencia de su autodestrucción. Es llamativo, por tanto, que los planos de apertura de la cinta compongan una comedida colección de caricias y de gestos esencialmente íntimos a propósito del cuerpo, como si antes de atravesar el punto 0 irreversible del asesinato se hubiera podido conjurar una suerte de ternura casi infantil (Fig. 07), o incluso de reconocimiento de una identidad a punto de quebrarse en el rostro mismo (Fig. 08).

Figuras 7 y 8. De la vida de las marionetas.

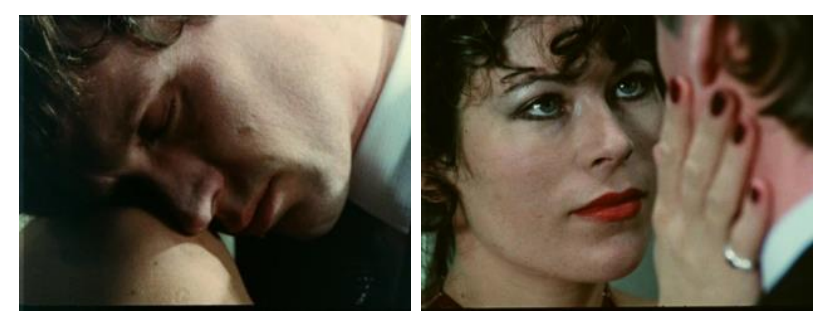

Fuente: Edición DVD de Filmax.

Como hemos podido contemplar, los procesos de focalización y punto de vista son extraordinariamente complejos en su negación explícita de otorgarle un saber "total" al espectador. Antes bien, este constante deslizamiento de la verdad se traduce en la disposición estructural-cronológica concreta del film, sobre la que podremos ordenar, al final, las implicaciones significantes del diseño narratológico. 


\subsection{Estructura cronológica}

Como apuntábamos anteriormente, la secuenciación del espacio-tiempo en la obra se despliega alrededor de un punto ciego de sentido (el asesinato de la prostituta). Mantiene con su cuerpo muerto una paradójica relación de necesidad y de contingencia: nunca sabremos a ciencia cierta qué materiales se nos muestran como explicación, como consecuencia o como puro azar en un flujo de vivencias que se resisten a la interpretación. Por poner un simple ejemplo, recordemos los planos dedicados a mostrar la actividad profesional de Peter (lexía 12). Partiendo de unos tumultuosos exteriores en plano picado por los que desfilan las luces de los coches alemanes regresando a casa al caer la tarde, se superpone la voz mecánica y desapasionada del hombre in media res. En ninguna ocasión se nos ofrece un contexto para sus decisiones, para la reflexión sobre sus términos burocráticos, esa especie de desapasionada jerga económica que fluye de modo robotizado hacia su secretaria. La escena se introduce entonces en el interior del despacho para mostrar al jefe desapasionado, al trabajador mecánico que farfulla una letanía de órdenes sin sentido tras las que podrían sobrevolar fragmentos de decisiones indescifrables -"costes", "honorarios", "excedentes", "balances"-, a medio camino entre la lógica kafkiana y el puro dislate. Huelga decir que la cámara de Bergman hace suya esta misma idea al encuadrar en violento contrapicado al protagonista (Fig. 9). Juega así con el techo como elemento escenográfico capaz de "oprimir" y de "atrapar" a su protagonista en un atributo formal que remite directamente al Orson Welles de El proceso (The Trial, 1962).

Figura 9. De la vida de las marionetas.

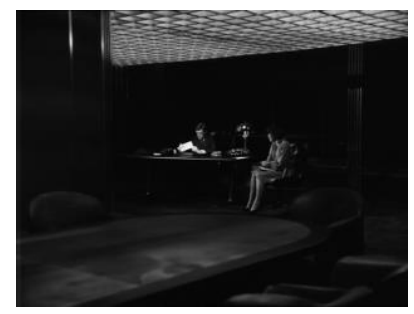

Fuente: Edición DVD de Filmax.

Esta escena nos sirve para poner de manifiesto la fragilidad de la cadena estructural significante. En efecto, a partir de ella se podrían desplegar muchas posibles lecturas del texto que justifiquen el asesinato - la vida desapasionada, el gesto gélido del capital, la alienación profesional que conduce a una desconexión inevitable con el propio cuerpo-, pero ninguna de ellas resulta lo suficientemente convincente para levantar una teoría firme. Otro tanto podría decirse de las lexías desplegadas alrededor de la convivencia marital, de la relación materno-filial o incluso de la propia salud mental del protagonista. Antes bien, el centro de sentido en el asesinato se mantiene siempre vacío, inaccesible. De hecho, el diseño bergmaniano conecta con las célebres reflexiones de Deleuze (1989) a propósito del despliegue estructural. Como apuntó el filósofo en una serie de sugerencias que serían ampliamente desarrolladas posteriormente por el primer Lacan, el punto de unión de la cadena significante es, necesariamente, un espacio vacío. Antes que cohesionar, la muerte de la prostituta actúa como una fuerza inaprehensible sobre el resto de las lexías que permite su ordenación y gestiona las líneas de atracción y rechazo narrativas experimentadas por los personajes. Es por ello que la disposición cronológica deba avanzar y retroceder al mismo tiempo a lo largo del metraje, dislocando así las dimensiones del tiempo del relato y el propio tiempo de visionado. 
Dicho con mayor precisión, es precisamente a través de la catástrofe como los hechos anteriores al asesinato adquieren su propio sentido. Se debe alterar la relación de casualidad narrativa para que los diálogos cobren su propia lógica, para que los gestos de los personajes adquieran un dramatismo mucho más concreto. Por ejemplo, cuando Tim se pregunta por su propio rostro y por la vivencia de su propio cuerpo varios días antes de que Peter estalle, no podemos separar sus monólogos de esa presencia inevitable (la mujer muerta).

Si volvemos a la tabla inicial con la que abríamos el artículo, podemos apreciar cómo existe una muy elocuente disrupción en la manera en la que la cinta maneja los distintos tiempos del relato. Por una parte, aquellos fragmentos que se encuentran localizados antes del asesinato se ordenan de manera rigurosamente cronológica y reducen cada vez más su distancia entre sí. De las dos semanas que preceden al crimen (lexías 5 a 8) a los cincuenta últimos minutos de $\mathrm{K}$ (lexías 21 a 24), el tiempo y la frecuencia se comprimen cada vez más y con mayor virulencia. La atracción inevitable hacia el asesinato se convierte en una pauta de montaje hasta que la película se siente obligada a hablar de "minutos" en lugar siquiera de "horas".

Al contrario, el territorio posterior al asesinato se muestra evanescente, incluso desprovisto de su lógica causal: los eventos que ocurren tres días después (Lexía 15) se muestran por montaje después de los que ocurren una semana después (Lexía 9), por no hablar de que generalmente incluyen dentro otros flashbacks (Lexía 10) a los que, como veremos en el siguiente epígrafe, resulta complejo remitirse con claridad. El futuro, además, distancia progresivamente la mostración de los acontecimientos. No en vano, la cinta se cierra con la visita final entre Katarina y Morgan en el psiquiátrico (Lexía 26), una vez que ya ha regresado el color.

Esta precisa vertebración cronológica - un pasado cada vez más veloz que avanza en línea recta hasta lo inevitable, un futuro confuso y moroso que se va demorando cada vez más en los acontecimientos-, nos parece una extraordinaria metáfora estructural del propio proceso vivido por Peter. En efecto, por mucho que hayamos recorrido todas las dislocaciones ya mencionadas en el sistema de narradores y en los procesos de focalización, la propia lógica del montaje - esto es, de la mostración- de los acontecimientos está conectada con la experiencia de Peter. Mientras él mismo intenta comunicar a los demás en el pasado la constante presencia de esa amenaza que le rodea y que no sabe gestionar -la tentación, el vértigo, el fantaseo constante hacia el crimen-, la percepción delirante de su cuerpo y de su tiempo tras la catástrofe se mezcla en un carrusel confuso de percepciones traducidas en su mecánica de alienación hospitalaria.

Figuras 10. De la vida de las marionetas.

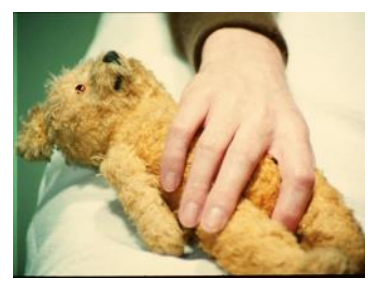

Fuente: Edición DVD de Filmax.

Sin duda, la última imagen de la cinta (Fig. 10) resume con precisión esta misma tesis que hemos defendido: el hombre intenta aferrarse a ese resto de la infancia, del pasado, del tiempo que ya ha quedado atrás mientras reposa, ausente y dominado por la medicación, en un limbo en el que el tiempo se dilata y se vacía de todo sentido. 


\subsection{Flashbacks expositivos e independientes}

La taxonomía del flashback en la que nos basamos tiene su origen en diversas fuentes. Aunque partimos de las contribuciones de referentes en la narratología como Genette (1998, 2004), Branigan (1992), Bordwell (1996), Gaudreault y Jost (1995) y Turim (1989), nuestra clasificación se inspira en la investigación de Luchoomun (2012: 20-65), sobre la cual efectuamos un ejercicio de síntesis y reformulación, además de incorporar conceptos propios. Esta clasificación resultante está desarrollada con detalle tanto en Planes Pedreño (2018: 91-92) como en Planes Pedreño y Rodríguez Serrano (2019: 106107). A partir de los contornos teóricos, categorías y criterios de medición allí delineados, en De la vida contabilizamos diez remembranzas, con las cuales el relato se remonta a distintos puntos temporales previos al asesinato perpetrado por Peter. O lo que es lo mismo: diez sucesos que acaecieron antes de lo que el film denomina la catástrofe. Por añadidura, en el marco de dos de estas remembranzas se ubican otros cinco flashbacks. Es decir, en cinco ocasiones nos encontramos frente a flashbacks dentro de flashbacks. Por tanto, podemos dividir la obra entre las analepsis principales (diez) y aquellas acomodadas en el interior de dos de esas diez (las cinco aludidas, distribuidas en dos escenas). En definitiva, la suma total es quince regresiones.

En cuanto a las tipologías predominantes del flashback, partimos de cinco clases alumbradas en los aludidos estudios: independientes -retrocesos en el relato a resultas de maniobras puramente enunciativas-; expositivos -sucesos pretéritos a raíz de narraciones emprendidas por personajes-; delimitados -analepsis espoleadas en función de situaciones u objetos específicos-; oníricos -regresiones que surgen en el marco de procesos inconscientes-; indefinidos -incidentes del pasado evocados por un personaje sin vinculación alguna con las condiciones en que este se halla-.

En el film de Bergman, dos únicas categorías de estas cinco se alternan de un modo equitativo:

- Siete flashbacks son independientes, esto es, no están ligados a las experiencias recordatorias de los personajes, sino que emergen por la acción del meganarrador.

- Ocho son expositivos, lo cual quiere decir que las visualizaciones de hechos de carácter pretérito se derivan de narraciones canalizadas por alguno de los personajes inmersos en el universo diegético de la película. Esos personajesnarradores serán: Peter (cinco ocasiones), su madre (dos) y el Dr. Jensen (una ocasión). Las ocho analepsis están acompañadas, además, por las voces en off de estos personajes, respectivamente.

Antes de afrontar el análisis específico del flashback, es indispensable que nos detengamos en un rasgo que, amén de reiterado, resulta crucial en el revestimiento formal del film: la pantalla de color negro en la que se incluye un breve intertítulo con vistas a conocer la ubicación temporal de cada escena. El relato se articula a través de la sucesión de los siguientes doce saltos temporales, de los cuales seis son hacia el futuro (la serie de entrevistas que dirige el comisario a personas que forman parte del entorno del protagonista, además de otros hechos), y otros seis hacia el pasado (acaecimientos previos al asesinato de K. que giran alrededor de la vida del personaje principal o de sus allegados). Cada uno de los intertextos tiene una función esencialmente informativa, si bien es necesario mencionar que dos de ellos hurtan al espectador las coordenadas espaciotemporales de su desarrollo: la séptima (Lexías 16/17, referentes a la carta fantaseada de Peter) y la doceava (Lexías 25 y 26, referentes al epílogo de la cinta).

Pese a que la inmensa mayoría de los flashbacks otorgan una información explícita y clara al espectador, aquellos que rasgan la cronología de la cinta resultan 
narratológicamente más interesantes. Es en ellos precisamente en los que se experimenta la ruptura del despliegue estructural, aquellos en los que se hace más evidente la falta de sentido y en los que, de alguna manera, se permite realmente un encuentro afectivo de gran complejidad con la vida emocional de los protagonistas.

Tomemos como ejemplo el comprendido entre las lexías 25 y 26: aquel que reza "Peter Egermann escribió una carta al Dr. Jensen (nunca se envió)". Quizá puede ser discutible concebir como flashback la escena que sigue a esas palabras impresas sobre la pantalla; al fin y al cabo, lo que contemplaremos será una producción imaginaria de Peter pronunciando el texto de la misiva que nunca llegó a su destinatario. Sin embargo, debido a que su escritura aconteció antes de la fatídica acción del protagonista, consideramos justificado entender esta escena como un incidente del pasado, así como otros sueños relatados por el protagonista, en los cuales, si bien la condición de estos es esencialmente onírica, el hecho de evocarlos a posteriori los transforma en retrospecciones.

En todo caso, las seis analepsis mencionadas gozan, como hemos señalado, de una descollante relevancia formal frente a las restantes, habida cuenta de que están antecedidas por intertítulos, de ahí que se constituyan en los bloques narrativos nucleares de la obra. Sin duda, debemos plantearnos las razones que subyacen a la específica codificación de estas seis regresiones, la misma que prevalece en las escenas con las que progresivamente se va a ir produciendo un alejamiento del suceso desencadenante a través de interrogatorios y conversaciones posteriores. Profundizar en las causas de esta codificación nos conduce a dilucidar las causas de la estructura narrativa en su totalidad, con los consiguientes problemas de codificación.

Durante los primeros fragmentos, parece que De la vida va a ceñirse al patrón narrativo de obras como Ciudadano Kane (Citizen Kane; Orson Welles, 1941) o Forajidos (The Killers; Robert Siodmak, 1946) o La cosecha estéril (La Commare Secca; Bernardo Bertolucci, 1962), sustentadas en investigaciones en las que se llevan a cabo entrevistas que despliegan flashbacks y generan una focalización múltiple. Pero a diferencia de estas, en el film del director sueco la averiguación del comisario resulta un hilo conductor que se desbarata poco a poco entre pasajes pretéritos de diverso signo. El agente de la ley no solo carece de cualquier atisbo de relevancia en el relato (su presencia en campo solo es identificada una única vez), sino que a las confesiones (del Dr. Jensen, de la madre de Peter y de Tim), y también a los seis referidos flashbacks, se unirán otros incidentes de distinta naturaleza, como la aludida recreación de la carta nunca remitida por el personaje principal, la escena en que el Dr. Jensen ofrece una interpretación clínica sobre el comportamiento delictivo de Peter y la visita de Katarina a la cárcel. Así las cosas, la empresa de la máxima autoridad de la diégesis quedará interrumpida y se saldará con un rotundo fracaso.

Hemos venido indicando que la película presenta una disposición consistente en una miscelánea de cuadros o retazos de vida, los cuales emergen, unas veces con anterioridad, otras con posterioridad, al punto cero del relato. Pero debemos apresurarnos a recalcar ahora que la independencia o autonomía de esas secciones se ve fortalecida por las separaciones, y al mismo tiempo por las pausas, originadas por la inserción de los intertítulos. El aislamiento formal de estos episodios prospectivos y retrospectivos invita a pensar en un encerramiento de los individuos que los integran, a inferir una correlación entre la prisión física a la que ha sido confinado Peter y la prisión metafórica en la que se encuentran sumidos sus allegados.

Si De la vida de las marionetas constituye una obra harto perturbadora es a causa de que lo que en realidad irá desvelando a partir de ese relevo de testimonios, evocaciones y 
acontecimientos pretéritos: el desvelamiento no tendrá que ver tanto con el motivo que impelió a Peter a acabar con la vida de K. como con el conflicto interior, de raíz existencial, que anuda a los principales miembros de la diégesis: la dificultad de conciliar la necesidad de ofrecer amor y afecto a los semejantes (y de recibirlos de estos) con unos ingobernables impulsos de destrucción hacia los mismos. Así pues, el trenzado formal de Bergman no está edificado a fin de resolver un enigma de carácter individual, sino, más bien, uno de carácter colectivo: la totalidad de los personajes devienen en insignificantes marionetas constreñidas por lo paradójico de sus actitudes emocionales -unas fuerzas incontrolables, en palabras del propio Tim- que son incapaces de dominar. Por consiguiente, el auténtico diagnóstico final trasciende los límites de la premisa dramática vinculada a Peter y acaba ampliándose a sus familiares y amigos. Ni qué decir tiene que el parte clínico que en el tercer acto desarrolla el Dr. Jensen en torno al perfil psicológico de Peter supone una suerte de salida fácil (y nada convincente) que no descifra el malestar colectivo que hemos avistado a través de las ideas y venidas de la narración.

Resulta elocuente el modo en que esta verdad colectiva es entregada al espectador sin que los personajes de la ficción (incluido el comisario) sean conscientes de ella, lo que da lugar a una contraposición muy acentuada entre el saber del primero y el de los segundos. Si nos atenemos, por ejemplo, a los testimonios transmitidos al policía por el Dr. Jensen, la madre de Peter y Tim, y también a las aportaciones de los flashbacks expositivos que generan algunas de sus narraciones, percibiremos que, en realidad, estos poco o nada esclarecen en lo tocante a la raíz del suceso capital que vehicula la trama, ni a través de sus palabras ni a través de sus imágenes. No es casualidad, por el contrario, que los flashbacks expositivos auspiciados por el protagonista sean los únicos que se aproximen a esa escisión emocional que desgarra a todas las criaturas de De la vida. En dos puntos distintos del relato, Peter rememora dos turbadores sueños en los que, junto a su mujer en una localización indeterminada, de intenso color blanco, emergen con claridad las pulsiones que le están devorando: en el primero de ellos, relatado al Dr. Jensen, refiere el placer que siempre ha experimentado al contemplar a su mujer "incluso cuando nos odiábamos o cuando estaba desagradable, borracha, enferma o enfadada", aunque al final del mismo empuña una cuchilla que lleva al cuello de Katarina; en el segundo, los gestos de ternura se contraponen tanto a ataques violentos entre ambos como a sentimientos de rencor, tras los cuales da muerte a su esposa. La estetización desmesurada de estas escenas - que se vale de los cuerpos desnudos y una iluminación en blanco y negro de clave alta que remite a ciertos gestos discursivos del relato publicitario de los setenta y los ochenta (González Requena y Ortiz de Zárate, 2007)- contrasta con la fealdad manifiesta de las escenas rodadas en color, en las que cristaliza con toda brutalidad la dimensión real e ingobernable del trauma. El hundimiento psíquico final de Peter, convertido en una suerte de autómata que juega mecánicamente al ajedrez con una computadora, da buena cuenta de la quiebra de los marcos éticos, personales y simbólicos de su universo. La metáfora del ajedrez como juego, con unas reglas verificables de pensamiento, acción y control, emerge como una irónica y desoladora referencia al caos vivencial de lo real que se ha manifestado alrededor del personaje durante toda la cinta.

\section{Conclusiones}

Llegados a este punto, estamos en disposición de sintetizar las principales aportaciones de nuestro análisis a propósito de la cinta de Bergman. En primer lugar, hemos efectuado una exploración sobre la quiebra de la estructura cronológica lineal en un doble movimiento: por un lado, sumándonos a las intuiciones de Deleuze y Lacan a propósito del centro vacío de toda estructura como condición previa para que emerja y circule el 
sentido -aquí, el asesinato de K. y su cadáver como punto límite del horror-, y por otro, en la riqueza de la focalización múltiple mediante un sistema de narradores complejo que no se somete a una distribución cronológica reconocible. Nos parece, por tanto, que la lógica discursiva en la gestión de la información no es solo un mecanismo propio del cine moderno destinado a poner en crisis los mecanismos en apariencia transparentes de la enunciación clásica, sino que atenta directamente contra nuestra manera de experimentar los traumas y la imposibilidad de suturarlos por completo en el marco del relato clásico.

En segundo lugar, nuestra aproximación al sistema de narradores y tiempos desplegados quebradamente ha hecho emerger la problemática central del film: la ausencia de sentido, la angustia misma que se asienta en los mecanismos laborales, productivos, familiares y matrimoniales de los sujetos de las sociedades contemporáneas. Pero, si algo queremos poner precisamente de relieve es que dicha angustia no depende tanto del asesinato de K. o de los larguísimos y complejos parlamentos que los personajes intercambian entre ellos. $\mathrm{Al}$ contrario, el gran hallazgo de Bergman es que la sensación de desgarro emerge de la escritura fílmica misma, esto es, de la gestión de los materiales estrictamente formales de la puesta en forma audiovisual. Es precisamente la aparente distancia del gesto ordenador -los intertítulos y su impostada "objetividad", el desmenuzamiento de los materiales narrativos-, lo que en realidad deshumaniza a la víctima y a los protagonistas principales. Formulado con más claridad: es la estructura la que bloquea cualquier flujo empático entre relato y espectador.

Esta superioridad de la enunciación y de sus maniobras como vía para dotar de sentido a la pesadumbre que experimentan (sin lograr entenderla) el grupo de marionetas que deambulan errantes por el film tiene su eco en las implicaciones derivadas de la confrontación entre los flashbacks generados por estas (expositivos) y los que son el resultado de las elecciones del meganarrador (independientes). En términos de duración, la desigualdad entre ambos tipos de regresiones es abrumadora, puesto que las primeras (siete) suman un total de alrededor de ocho minutos frente a la hora y tres minutos de las segundas (ocho). Lo que esta desproporción deja entrever es la insignificancia del recuerdo de los personajes en su propósito de dar respuesta al comportamiento delictivo de Peter, y, al mismo tiempo, la magnitud de los episodios rescatados por las instancias creativas del film: las evocaciones de los personajes no contribuyen a erigir ningún tipo de discurso que esclarezca la cuestión central que sobrevuela a lo largo de la película, a diferencia de los retrocesos desencadenados por las instancias enunciativas, los cuales sí componen un valioso repertorio de sucesos pretéritos con los que es posible discernir las raíces del malestar colectivo, que no individual, que los aflige.

A la postre, los personajes se esfuerzan por dotar de lógica a sus sentimientos; pero sus opacos razonamientos (y consecuentemente, los pasajes retrospectivos a los que se retrotraen) no consiguen acceder al núcleo de sus fracturas y tensiones. En consecuencia, con respecto a la resolución del interrogante de la obra, los incidentes pasados que son recuperados por el meganarrador sin la mediación de los personajes cobran más valor que los suministradas por estos. Por ello, en lo que a flashbacks se refiere, el corolario sería que las siete analepsis independientes resultan mucho más trascendentales que las ocho expositivas. 


\section{Bibliografía}

Astor, D. (2018). Nietzsche: La zozobra del presente. Barcelona: Acantilado.

Aumont, J. y Marie, M. (1990). Análisis del film. Barcelona: Paidós.

Barthes, R. (1980). S/Z. Madrid: Siglo XXI de España.

Barthes, R. (1985). La aventura semiológica. Barcelona: Paidós.

Berenstein, A. (2011). La construcción del relato de la melancolía en el imaginario cultural. Trama\&Fondo, 30, pp. 103-108. Recuperado de: http://bit.ly/2YBmlLF

Bergman, I. (1946). Jack hos skandespelarna. Estocolmo: Bonniers.

Bergman, I. (2001). Imágenes. Barcelona: Tusquets.

Bordwell, D. (1996). La narración en el cine de ficción. Barcelona: Paidós.

Branigan, E. (1992). Narrative Comprehension and Film. London: Routledge

Brecht, B. (2004). Escritos sobre teatro. Barcelona: Alba.

Casetti, F. (1989). El film y su espectador. Madrid: Cátedra.

Català Domènech, J. M. (2016). La gran espiral: Capitalismo y paranoia. Vitoria: Sans Soleil.

Company, J. M. (1999). Ingmar Bergman. Madrid: Cátedra.

Deleuze, G. (1989). Lógicas del sentido. Barcelona: Paidós.

Díez Puertas, E. (2006). Narratividad fílmica. Escribir la pantalla, pensar la imagen. Madrid: Fundamentos.

Escudero, A. (2017). Heidegger en el laberinto de la modernidad. Madrid: Arena Libros. Font, D. (2002). Paisajes de la modernidad. Barcelona: Paidós.

Gado, F. (1986). The passion of Ingmar Bergman. Durkham: Duke University Press.

García Catalán, S. y Sorolla Romero, T. (2014). Morfologías de nuestros áridos días felices. L'Atalante, 17, pp. 46-52. Recuperado de: http://bit.ly/2yNTDrB

Gaudreault, A. y Jost, F. (1995). El relato cinematográfico: ciencia y narratología. Barcelona: Paidós.

Genette, G. (1989). Figuras III. Barcelona: Lumen.

Genette, G. (2004). Metalepsis. De la figura a la ficción. México D.F: Fondo de Cultura Económica.

Gómez Tarín, F. J. (2011). Elementos de narrativa audiovisual: Expresión y narración. Cantabria: Shangrila.

Gómez Tarín, F. J. (2018). Apocalipsis y melodrama: El tiempo suspendido y la herida final. L'Atalante, 25, pp. 41-53.

Gómez Tarín, F. J. y Marzal, J. (2015). Diccionario de conceptos y términos audiovisuales. Madrid: Cátedra.

González Hortigüela, T. (2017). Saraband: Más allá del fantasma materno. Trama\&Fondo, 43, pp. 145-156. Recuperado de: http://bit.ly/2ZNuLMb

González Requena, J. y Ortiz De Zárate, A. (2007). El espot publicitario: Las metamorfosis del deseo. Madrid: Cátedra. 
Heidegger, M. (2009). Ser y tiempo. Madrid: Trotta.

Humphrey, D. (2013). Queer Bergman: Sexuality, Gender, and the European Art Cinema. Texas: University of Texas Press.

Kinder, M. (1981). "From the life of the marionettes to The Devil's Wanton: Bergman's creative transformation of a recurring nightmare". Film Quarterly, 34 (3), pp. 26-37. Doi: $10.2307 / 1212035$

Krutnik, F. (2006). In a Lonely Street: Film noir, Genre, Masculinity. Londres: Routledge.

Machado, A. (2009). El sujeto en la pantalla: La aventura del espectador, del deseo a la acción. Madrid: Gedisa.

Marzal Felici, J. (2004). Guía para ver y analizar "Ciudadano Kane”. Valencia: Nau Llibres.

Metz, C. (2002). Ensayos sobre la significación en el cine (1964-1968) (Vol. I). Barcelona: Paidós.

Luchoomun, L. (2012). Mental Images in Cinema: Flashback, Imagined Voices, Fantasy, Dream, Hallucination and Madness in Film (Tesis inédita de doctorado). University of Roehampton, Londres. Recuperado: https://buff.ly/2ikTOGi

Lyotard, J.-F. (1986). La postmodernidad explicada a los niños. Madrid: Gedisa.

Orr, C. (2000). Scenes from the class struggle in Sweden: Persona As Brechtian Melodrama. En L. Michaels (Ed.), Ingmar Bergman's Persona (pp. 86-109). Cambridge: Cambridge University Press.

Palao-Errando, J. A., Loriguillo-López, A. y Sorolla-Romero, T. (2018). Beyond the screen, Beyond the Story: The Rhetorical Battery of Post-Classical Films. Quarterly Review of Film and Video, 35 (3), pp. 224-245. https://doi.org/10.1080/10509208.2017.1409097

Planes Pedreño, J. A. (2018). El presente devorado por el pasado: declinaciones del flashback metaléptico y sus resonancias en el discurso memorístico de La prima Angélica. Hispanic Research Journal, 19 (1), pp. 89-104. https://doi.org/10.1080/14682737.2018.1419005

Planes Pedreño, J. A. y Rodríguez Serrano, A. (2019): El espectro corporeizado: resonancias del flashback metaléptico en Fresas salvajes (Smultronstället, 1957). Trípodos, 44, pp. 105-120. Recuperado de: http://bit.ly/313wDkv

Puigdomènech, J. (2004). Ingmar Bergman: El último existencialista. Madrid: JC.

Rancière, J. (2010). El espectador emancipado. Pontevedra: Ellago Ediciones.

Rodríguez Serrano, A. (2017). Narrar el tiempo hacia la muerte. Análisis fílmico de Gritos y susurros (Viskningar och rop, Ingmar Bergman, 1972). Communication \& Society, 30 (3), pp. 13-28. Doi: 10.15581/003.30.3.13-28

Sjögren, H. (2002). Lek och raseri: Ingmar Bergman teater 1938-2002. Estocolmo: Carlssons Bokförlag.

Sontag, S. (1967). Persona. Sight and Sound, 36 (4), p. 186.

Steene, B. (2005). Ingmar Bergman: A reference guide. Amsterdam: Amsterdam University Press. 
Turim, M. (1989). Flashbacks in Film. London: Routledge.

Wood, R. (1994). Persona Revisited. Cineaction, 34, pp. 59-67.

Wood, R. (2009). Ingmar Bergman. Detroit: Wayne State University Press.

Zunzunegui, S. (2016). La mirada cercana: Microanálisis fílmico. Cantabria: Shangrila.

Zumalde, I. (2011). La experiencia fílmica: Cine, pensamiento y emoción. Madrid: Cátedra. 